\title{
MOTIVATION BEHIND INTERNATIONAL UNDERGRADUATE STUDENTS CHOOSING ENGINEERING
}

\author{
Juan Abellól, ${ }^{1,2}$, Alys Avalos-Rivera ${ }^{3}$, Gabriel Potvin ${ }^{2,4}$, Saloome Motavas ${ }^{2,5}$, \\ Vladan Prodanovic ${ }^{1,2,4}$, Sandra Zappa-Hollman ${ }^{3,6}$ \\ ${ }^{1}$ Department of Mechanical Engineering, University of British Columbia \\ ${ }^{2}$ Applied Science Stream, Vantage College Program, University of British Columbia \\ ${ }^{3}$ Academic English Program, Vantage College Program, University of British Columbia \\ ${ }^{4}$ Department of Chemical and Biological Engineering, University of British Columbia \\ ${ }^{5}$ Department of Electrical Engineering, University of British Columbia \\ ${ }^{6}$ Department of Language and Literacy Education, University of British Columbia \\ abello@mech.ubc.ca, alys.avalos@ubc.ca
}

\begin{abstract}
This paper reports on a pilot study that investigated what motivated a group of first-year international students in the Vantage College program at the University of British Columbia (UBC) to pursue a degree in engineering. The study also sought to examine whether students report changes in their motivation as a result of completing their first year in our program. Data were collected through an open-ended survey provided to our cohort of 69 students, from which we received 66 responses. The results were analyzed qualitatively based on an expectancy value theoretical framework (focused on interest, utility, cost, and attainment.) The findings showed strong agreement with interest and utility as motivating factors, little agreement with attainment and cost as relevant factors, and the presence of additional motivators not present in our initial framework. The strongest among the latter group was family influence, with ability also appearing, yet to a lower degree. Our results suggest that interest and utility are the strongest motivators (over one third of students), with family influence (about one quarter) and ability (about one eight) being less important. We found few instances of cost (about one tenth) and no significant instances of attainment; this may be because engineering identity is developed as a student progresses through the undergraduate program.
\end{abstract}

Keywords: career choice, international students, first year students.

\section{INTRODUCTION}

Vantage College (VC) at the University of British Columbia (UBC) offers first-year programs tailored to international students that are academically strong but whose language proficiency falls just short of that required for direct-entry into UBC programs. The students enrolled in these programs complete their first-year academic disciplinary requirements with additional embedded academic English instruction. For example, in the Applied Science (APSC) program in VC, most engineering content courses are linked to corresponding language courses that provide context-specific language instruction [1]. Upon successful completion of the VC program, students join their "direct-entry" counterparts at the beginning of their second year for the remainder of their studies.

The APSC stream in VC is relatively new, with the first cohort entering the program in 2015 [2]. As in any developing program, it is valuable to better understand the reasons why our students choose to pursue a degree in our field. This knowledge can help instructors and administrators better align our programs and services with student expectations [3], and to understand issues related to student persistence and non-persistence [4].

A few studies have focused on student motivation to pursue and persist in undergraduate engineering programs. Seymour and Hewitt determined that persisting students in the United States tended to choose science, math and engineering for reasons of interest, while non-persisting students tended to choose based on family influence, future earnings or ability in high-school mathematics and science [4]. Matusovich et al indicate the alignment with selfidentity is more important than interest when it comes to student persistence in engineering for students at an American university [5]. Yan and Berliner explored the motivation for Chinese students to seek a graduate degree in the United States [6]. Yet, there is a gap in the literature concerning the motivation of international students to pursue and persist during an undergraduate engineering degree in Canada.

\section{BACKGROUND}

There are several frameworks to understand career choice [7]. Following a similar approach to the one used 
by Matusovich et al, this study uses expectancy-value theory [8] within a motivational theory framework [9]. Motivational theory aims to explain the reasons why an individual follows a particular behavior [10]. Expectancyvalue theory helps illuminate these reasons by classifying them into four broad categories: interest (enjoyment), utility (future usefulness), cost (time and mental energy) and attainment (agreement with personal identity) [8][11]. Expectancy-value theory has been previously used to understand career choices [12].

\section{METHODS}

A survey containing two open-ended questions was deployed in Canvas (the LMS used for this course). The first question asked students to identify the reason why they chose to study engineering, and the second whether that reason had changed after completing the first year of their studies. (Please refer to the appendix of this document for the exact wording of the questions.) Sixtysix students chose to participate in this survey, which represents $96 \%$ of our 2018-2019 cohort of 69 students.

\subsection{Manual survey analysis}

Survey answers were anonymized, and three of the authors analyzed the data manually. We coded the answers to the first question (reason to study engineering) using the four pre-determined categories from motivational theory: interest, utility, cost, and attainment. We coded the answers to the second question (has the reason changed) without using pre-determined codes.

When analyzing responses to the first question, cost was the most difficult of the motivators to identify. Student answers were tagged to this code if the student chose engineering because there was a cost associated with choosing another option. For example, a student who chose to pursue engineering because not doing so means studying a field that the student does not wish to pursue was coded as "cost".

As we analyzed the data, it became clear that other categories not included in the four motivators listed above appeared often enough to be considered important. We decided to also consider these motivators, as described in the results section.

\subsection{Survey analysis using software}

Our initial coding for the first question was subsequently revised using NVivo 11 software to refine categories and highlight the most recurring trends in the data. An initial word frequency analysis allowed us to identify the word "interest" or any of its variations (e.g., interests, interesting, interested, etc.) as the second most prominent content word in the data for the first question (the most prominent word was "engineering"). An analysis of the context surrounding this word led us to classify the participants' manifested interests in 5 sub-categories:
1. Interest in science: Interest in pursuing scientific studies.

2. Interest in applied science: Specific interest in the application of scientific knowledge to build, design or create technological solutions for everyday problems.

3. Interest for a specific topic: A very specific interest such as "building cars", "studying circuits", etc.

4. Curiosity: Studying something unfamiliar or something that boosts the imagination.

5. Enjoyment: Expressed by words such as "love", "like", "hobby", "fun".

\section{RESULTS}

\subsection{Initial motivation}

The manual qualitative analysis of the student answers to the first survey question yielded five main motivators (figure 1): interest, utility, family, ability in high-school math and science, and ability in high-school math and science. The strongest motivators (interest and utility) coincided with our initial motivational theory framework; the third, fourth and fifth (tie) (family, high-school ability and high-school enjoyment) emerged from the data, and were thus not in our initial list of codes.

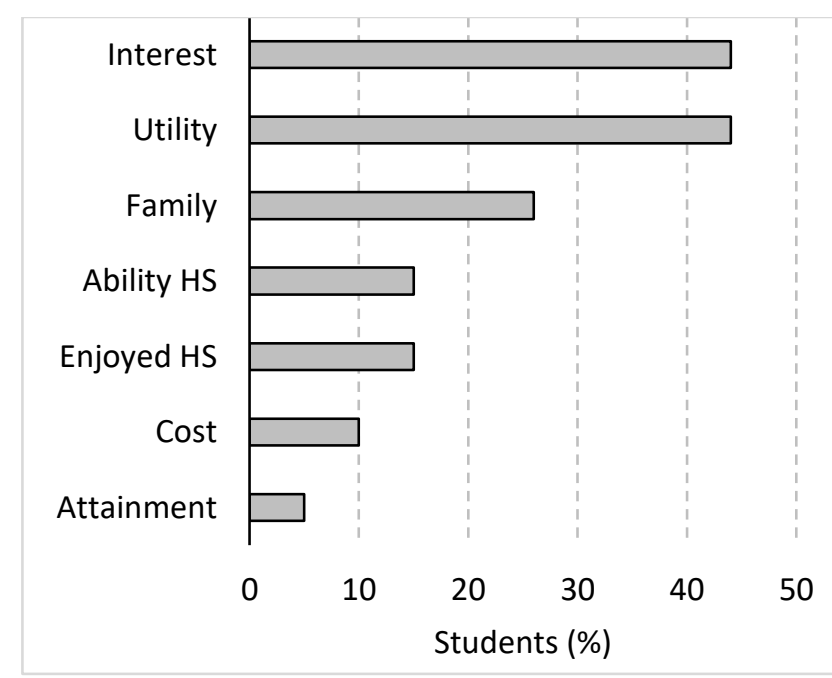

Figure 1: Common student motivators.

The most common motivators (over $40 \%$ of respondents) were interest and utility. Students in the interest group include those who enjoy practical activities related to the application of scientific knowledge to everyday problems (e.g. experiments, discovery, how things work) or have interest in specific engineering applications (e.g. computers, cars.) This set does not include students who chose engineering based on enjoyment of high-school math and science (physics, chemistry) alone. Over $60 \%$ of the interest respondents 
(16/26) made reference to engineering design (make, create, build).

Students in the utility motivator were drawn to engineering because they wished to apply scientific knowledge to solve everyday problems. Many of these students saw engineering as a profession with promising career prospects (breadth, availability, salary, travel). Over a third of the respondents that indicated a motivation coded as utility (14/27) were drawn to engineering because of its social impact (benefit society, serve others, solve problems that affects others). Other reasons corresponding to the utility motivator include a desire to work in the family business after graduation.

The third motivator (one quarter of respondents) was family influence. These students chose engineering because of family tradition (one or more parents or grandfather are engineers), parental advice, or a desire to please parents who wanted the student to be an engineer. About one quarter of students include family as a motivator; about one tenth of students indicate family as the sole motivator for studying engineering.

The fourth and fifth motivators (tie, at about one eight of respondents each, or 9/61) were ability and enjoyment of high-school math and science (chemistry, physics). Interestingly, only one out of nine students reported both ability and enjoyment of high-school math and science.

As mentioned earlier, we tagged a student response under the cost motivator if the student framed the reason for choosing engineering in terms of the opportunity cost for choosing something else. For example: students who chose engineering because arts would be more difficult due to language challenges, or a student who wished to be a lawyer but decided to study engineering instead because they had difficulties reading, writing and memorizing. This category also includes students who reported choosing engineering not because engineering was interesting, but because other fields were uninteresting. About one tenth of respondents (6/61) reported a cost motivator.

Attainment responses were rare, at about 5\% (3/61). These students chose engineering because they appreciated "being" or "becoming" an engineer. We classified these responses under attainment because the operational verbs related to personal identity (be, become) and the context in which these verbs were used suggested the participant aspired to become part of a professional community perceived as prestigious or respected. All students expressing an attainment motivator also chose interest as additional motivator.

Analyzing the data using NVivo qualitative analysis software revealed that not all of the participants' responses that had been coded in the "interest" category denoted one single type of interest. For example, in several cases, participants acknowledged that they were simultaneously attracted to the study of science in general while also having a more specific interest in the development of technology, as shown in the following excerpt:

"One of the big factor [sic] and reason that I choose engineering was that I had and still have a great affinity towards mathematics and physics. Also, the idea of building a projecting [sic] something from scratch is something that I like a lot."

\subsection{Changes in motivation}

A qualitative analysis of the responses to the second survey question (figure 2) indicates that over half (32/57) of students had not changed the reason why they chose engineering after completing their first year in our program.

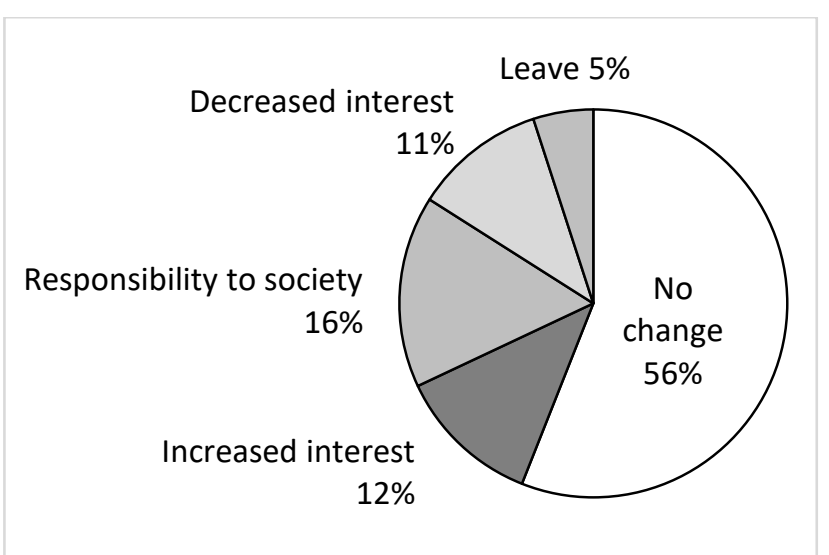

Figure 2: Changes in student motivation.

About one eight of students (7/57) reported increased interest in engineering over the course of their studies to date, with exposure to engineering applications, specific subjects (e.g. computer programming) or involvement in design projects being the reasons for increased interest.

Approximately $16 \%$ of respondents (9/57) changed their original reason and now also consider the social impact of engineering (social responsibility) as a motivator. This could be attributed to the nature of the program, either at the course, faculty or institutional level, since sustainability is considered a core concept and educational priority at each of those scales, or to external societal factors. These results present very interesting avenues for future study on teaching sustainability in engineering.

A handful of students reported a decreased interest in engineering due to the workload of engineering programs, stress, or the difficulty of the subject matter. Approximately $11 \%(6 / 57)$ of respondents expressed a decreased interest in the program, and 5\% (3/57)a desire to switch majors, with difficulty and workload being the main reasons for wanting to leave engineering. 
In general, students who perceived their experiences in the first year as positive expressed feeling encouraged to persist. In contrast, a couple of outliers did not refer to their experiences as the main factor to persist. In fact, they acknowledged that they were not particularly motivated to pursue a career in engineering, but had decided to continue in the program for other reasons such as family expectations or a perceived obligation to graduate.

\section{CONCLUSIONS}

Based on the analysis of the survey results, the strongest motivators of this cohort of engineering students to study engineering were interest, utility, and family. Interest and utility were consistent with our initial motivational theory framework, while family emerged from the collected responses. Interest and ability in high-school math and science are weaker motivators that also emerged from the data.

Over $40 \%$ of students chose engineering because of personal interest, with over $60 \%$ of these interest respondents mentioning their affinity for design. Over $40 \%$ of students mentioned the utility value of an engineering degree, with about half of the utility respondents emphasizing the impact of engineering on society. About one quarter chose engineering due to family influence, with about a tenth mentioning family alone. About an eight chose engineering due to their abilities in high-school mathematics and science, and about an eight due to their interest in these topics while in high school.

The motivation to study engineering remains unchanged after the first year for about hanf of students, with an eight indicating increased interest after their firstyear courses and 16\% adding the social impact of engineering to their reasons for studying engineering.

Over $40 \%$ of students chose engineering based on persistence motivators (interest, attainment) while $16 \%$ of students chose based on non-persistence motivators alone (family influence, future income, ability in high-school math and science.) Out of the three students who expressed to leave engineering after their first year, two had chosen this field based on non-persistence motivators alone.

A relatively low number of students reported decreased interest in engineering or a desire to switch to other programs, which suggests that UBC and Vantage College are doing an adequate job at screening applications and selecting good candidates for admission.

Motivation is of course a complex subject that cannot adequately be characterized from the results of a single two-question survey. Having said that, the results in this paper do present some interesting future avenues of research. The motivational framework used, for example, did not include family influence as a main motivator. Although anecdotally engineering instructors are aware that this plays a role in some students' decision to study engineering, the significant preponderance of responses identifying family influence on their decision-making process may suggest that this has particular importance for international students, perhaps due to cultural or social predispositions different than those of domestic students in Canada. This is an important question to study in order to help identify the best candidates for engineering programs (i.e. those best suited to the profession and studies).

Since Vantage APSC is also a very multicultural learning environment, with students in this cohort coming from more than a dozen countries, it would be interesting to follow-up this study with one-on-one interviews, to determine whether there are any correlations between country of origin and specific stated motivational factors, or between specific motivational factors and academic performance in core engineering courses. Since secondyear placement is a competitive process, and since students must rank their choices of disciplinary specialization, it would also be interesting to determine whether there are any correlations between stated motivations, academic standing and performance, and preferred career path (e.g. whether specifically mentioning sustainability and a stated desire to help the environment correlates with specific disciplines or other motivating factors).

As previously mentioned, Vantage APSC is a young program, and this pilot study serves as a starting point to further investigations on student motivations both within the Vantage program and the international student community in Canada in general.

\subsection{Limitations}

The limitations of this study include the fact that Vantage has cohort that is composed entirely of international students, which means that respondents may have motivations different from those of general-entry first-year international students. Given the nature of the program, some limitations in English-language proficiency may have an impact on the perceived sophistication of student answers, which may have allowed for some nuances in student thinking to go undetected. Since the study was only conducted with a single cohort of students, all having undergone a common first year, it would be interesting to repeat this study with future cohorts to analyze any differences in student responses.

\section{References}

[1] "Engineering | UBC Vantage College." [Online]. Available:

https://vantagecollege.ubc.ca/engineering. [Accessed: 06-May-2018].

[2] M. Murphy and G. Potvin, "Building bridges: an approach to the integration of English language education in first-year applied science courses for international students," in Proc. 2016 Canadian Engineering Education Association Conference, 2016. 
[3] H. T. Holmegaard and L. Ulriksen, "Why Students Choose (Not) To Study Engineering," no. September, pp. 1-9, 2010.

[4] E. Seymour and N. M. Hewitt, Talking about leaving: why undergraduates leave the sciences. Westview Press, 1997.

[5] H. M. Matusovich, R. A. Streveler, and R. L. Miller, "Why Do Students Choose Engineering? A Qualitative, Longitudinal Investigation of Students' Motivational Values," J. Eng. Educ., vol. 97, no. 4, pp. 289-304, 2010.

[6] K. Yan and D. C. Berliner, "Chinese international students in the United States: Demographic trends, motivations, acculturation features and adjustment challenges," Asia Pacific Educ. Rev., vol. 12, no. 2, pp. 173-184, 2011.

[7] R. Lent, G. Hackett, and S. Brown, "A social cognitive framework for studying career choice and transition to work.," J. Vocat. Educ. Res., vol. 21, no. 4, pp. 3-31, 1996.

[8] J. Eccles, "Subjective Task Value and the Eccles et al. Model of Achievement-Related Choices," in Handbook of competence and motivation, A. J. Elliot and C. S. Dweck, Eds. Guilford Press, 2005, p. 704 .

[9] R. G. Gheshlagh et al., "The Relationship Between Mental Health and Resilience: A Systematic Review and Meta-Analysis," Iran Red Crescent Med J., vol. 2030, no. 14, 2017.

[10] T. R. Mitchell, "Motivation: New Directions for Theory, Research, and Practice," Acad. Manag. Rev., vol. 7, no. 1, p. 80, Jan. 1982.

[11] J. Eccles, "Who am I and what am I going to do with my life? Personal and collective identities as motivators of action," Educ. Psychol., vol. 44, no. 2, pp. 78-89, 2009.

[12] J. Eccles, "Gendered educational and occupational choices: Applying the Eccles et al.1 model of achievement-related choices," Int. J. Behav. Dev., vol. 35, no. 3, pp. 195-201, 2011.

\section{APPENDIX A: SURVEY QUESTIONS}

1. Remember the time before you came to UBC. Present the reason(s) why you chose to study engineering at that time. Elaborate on all factors that may have played a part in your decision.

2. Now consider your experiences this past year at UBC. Have these experiences changed the reason(s) why you want to study engineering? Describe these changes, if any, and explain why your initial reasons have or have not changed during this year. 